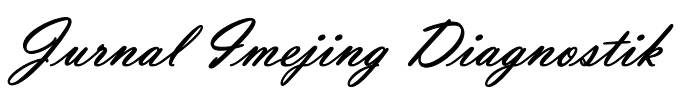

e-ISSN 2621-7457, p-ISSN 2356-301X

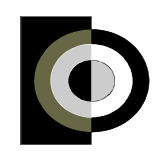

http://ejournal.poltekkessmg.ac.id/ojs/index.php/jimed/index

\title{
Teknik Pemeriksaan Kedokteran Nuklir Bone Scan di Instalasi Radiologi RSUP Dr. Kariadi Semarang
}

\author{
Nanik Sudaryatmi ${ }^{1}$, Siti Masrochah ${ }^{2}$, Muhammad Erfansyah ${ }^{3}$ \\ ${ }^{1}$ RSUD Dr. Kariadi Semarang, Indonesia \\ 2,3 Poltekkes Kemenkes Semarang, Indonesia \\ Corresponding author: Nanik Sudaryatmi \\ e-mail: naniksudaryatmi.@gmail.com
}

Received: January $30^{\text {th }}$, 2021; Revised: January $31^{\text {st }}$, 2021; Accepted: February $1^{\text {st }}$, 2021

\begin{abstract}
Background: A bone scan or commonly referred to as bone print is nuclear medicine examination using a radioactive substance or radiopharmaceutical that is inserted into the body through intravenous injection which aims to help diagnose abnormalities that occur in the bone. This imaging procedure uses a radiopharmaceutical 99mTc-MDP (methylenediphosphonate) is the most commonly used radiopharmaceutical.

Methods: The patient will be injected with this radiopharmaceutical at a dose of $15-20 \mathrm{mCi}$, through the vein in the hand. Imaging can be done as soon as the radiopharmaceutical is injected or after a while to wait for the radiopharmaceutical to be distributed and absorbed by the bone, about 3-5 hours later. Imaging is done by three-phase method, namely the first phase (Vascular phase), the second phase (Blood Pool phase), and the third phase (Total body phase) 1.

Results: The bone scan method is an efficient examination because in $1 \mathrm{x}$ the imaging can provide a complete picture from the head to the foot. Evaluation of results, under normal conditions the distribution of radioactivity in the bone appears symmetrical.

Conclusion: In the process of bone metastasis, it can be seen that typical pathological radioactivity can be multiple (multiple hot spots). Malignant tumors can be distinguished from benign tumors by blood pool examination.
\end{abstract}

Keywords: bone scan; radiofarmaka; kelainan tulang.

\section{Pendahuluan}

Pemeriksaan bone scan merupakan pemeriksaan yang sangat sensitif dibandingkan dengan foto sinar- $X$ dan secara rutin telah digunakan. Namun pemeriksaan ini memerlukan waktu yang lama dan biaya yang relatif tinggi. Secara spesifik, bone scan atau sidik tulang biasanya dilakukan untuk melihat ada tidaknya masalah pada metabolisme tulang yang merupakan proses penghancuran tulang dan pembentukannya kembali. Saat tulang rusak atau patah, maka tulang baru akan terbentuk sebagai proses penyembuhan. Bone scan merupakan teknik yang baik untuk melihat apakah aktivitas ini berjalan baik atau tidak (D, 2011).

Selain itu, bone scan juga biasa digunakan untuk melihat apakah suatu kanker sudah menyebar ke tulang dari bagian lain tubuh. Penilaian jauh tidaknya penyebaran kanker (staging) penting bagi dokter. Informasi ini nantinya akan berguna dalam memilih terapi yang tepat untuk pasien (Masjhur \& Hussein, 1999). Oleh karena itu, pasien dengan riwayat keganasan perlu waspada terhadap penyebaran sel kanker ke tulang. Terlebih, jika muncul gejala nyeri yang tidak wajar dan tulang mudah patah, maka untuk segera memeriksa penyebaran kanker pada tulang melalui pemeriksaan bone scan. Metode bone scan merupakan pemeriksaan yang efisien karena dalam 1x pencitraan mampu memberikan gambaran utuh mulai dari tulang kepala sampai kaki (Yudistiro, 2012).

Pemeriksaan bone scan dianjurkan dilakukan secara berkala pada pasien dengan keganasan yang sering metastasis ke tulang seperti kanker kelenjar prostat, payudara, dan paru (Jana \& Blaufox, 2006). Biasanya, pemeriksaan kesehatan (chcek up) rutin sekali setahun dengan bone scan tidak diperlukan kecuali kalau ada gejala yang tidak biasa dirasakan sebelumnya, seperti rasa nyeri yang menetap dan tidak membaik dengan obat anti nyeri biasa (Van den Wyngaert et al., 2016). 
Indikasi dilakukan pemeriksaan bone scan antara lain fraktur yang sulit ditemukan, radang sendi (arthritis), infeksi pada tulang (osteomylitis), kanker yang berasal dari tulang, (paget's diseasa) penyakit yang menyebabkan tulang menjadi lemah dan berubah bentuk, metastasis pada tulang (kanker yang menyebar ke tulang dari bagian tubuh lain), matinya jaringan tulang akibat kekurangan suplai darah (nekrosis avaskuler), kondisi yang menyebabkan jaringan bekas luka yang abnormal tumbuh di bagian tulang yang sehat (fibrous dysplasia), dan tumor tulang Primer. Sedangkan untuk kontraindikasi pemeriksaan bone scan antara lain ibu hamil dan menyusui, pasien yang 24-48 jam sebelumnya telah dilakukan pemeriksaan dengan Tc-99, dan pasien yang mendapatkan kontras media dari pemeriksaan sebelumnya (Masjhur \& Hussein, 1999).

Radiofarmaka yang paling sering digunakan untuk pemeriksaan bone scan adalah Tc99m-MDP (methylenediphosphonate) sebanyak $15-20 \mathrm{mCi}$. Radiofarmaka ini disuntikkan ke dalam tubuh secara intravena akan ditangkap oleh sel-sel osteoblast. Mekanisme penangkapan radiofarmaka tersebut bergantung pada kemampuan zat tersebut berikatan dengan ion-ion organik dan reaksinya dengan berbagai bentuk organik pada tulang. Atas dasar mekanisme inilah, maka pemeriksaan bone scan menjadi sangat sensitif dibandingkan dengan pemeriksaan radiologi yang didasarkan adanya perubahan anatomi (Weiner, 2006).

Radiofarmaka yang disuntikkan memancarkan radiasi dalam jumlah yang sangat kecil. Bahkan, risiko mengalami alergi terhadap radiofarmaka tersebut sangat rendah. Oleh karena itu, pemeriksaan ini tidak memiliki resiko yang lebih besar dibanding pemeriksaan foto sinar-X biasa. Pasien tidak perlu khawatir terhadap paparan radiasi dari pemeriksaan ini. Radiasi yang tidak terpakai akan terbuang saat pasien buang air kecil atau besar. Apabila tidak terbuang dengan cara tersebut, dalam waktu enam jam jumlah radiasinya secara otomatis berkurang separuhnya hingga ke batas aman (Shie et al., 2008).

Keunggulan pemeriksaan bone scan atau sidik tulang adalah dapat mendeteksi kelainan yang terjadi pada tulang 3-6 bulan lebih awal sebelum terjadi kerusakan tulang akibat proses keganasan, selain itu dengan sidik tulang dapat mendeteksi kelainan yang terjadi pada seluruh tulang tanpa menyebabkan paparan radiasi yang berlebih karena pemeriksaan sidik tulang dilakukan dengan pencitraan seluruh tubuh (whole body imaging) terutama pada kasus yang tidak diketahui sumber fokus nyeri (Cheran et al., 2004).

Fase-fase pencitraan bone scan dilakukan dengan metode tiga fase yaitu fase vaskuler, fase blood pool, dan fase total body. Fase vaskuler (fase pertama) dilakukan pada posisi pasien tidur terlentang dengan detektor ditempatkan pada bagian tubuh yang akan diperiksa berada diatas lapang pandang detektor. Pemeriksaan fase pertama merupakan pemeriksaan dinamik dalam frame berukuran matrix $128 \times 128$ dengan waktu pencacahan 3 detik/frame selama 2 menit. Posisi pencitraan posisi anterior atau posterior, pencitraan dimulai bersamaan dengan saat penyuntikkan radiofarmaka secara bolus (GE Medical Health, 2005a).

Fase blood pool (Fase kedua) dilaksanakan segera setelah fase pertama selesai berupa pencitraan statik dalam frame berukuran matrix 256x256 sebanyak 700 Kcounts dengan posisi pencitraan anterior dan posterior. Fase total body (fase ketiga) merupakan pemeriksaan statik yang dilakukan 3-5 jam pasca penyuntikan radiofarmak. Sebelum memasuki ruang pemeriksaan pasien dianjurkan untuk buang air kecil dengan hati-hati untuk menghindari kontaminasi. Pada fase ketiga ini dilakukan pemeriksaan seluruh tubuh (whole body scan) dari posisi anterior dan posterior dilanjutkan dengan pemeriksaan spot pada bagianbagian yang mencurigakan, misalnya spot paru oblik. Jika terlihat ada penangkapan yang tinggi pada daerah tertentu, dilakukan pengambilan gambar dengan tomo-spect CT pada daerah tersebut. Pemeriksaan dalam frame berukuran matrix 256x256 sebanyak 700 Kcounts (GE Medical Health, 2005b).

\section{Metode}

Pemeriksaan bone scan di Instalasi Radiologi RSUP Dr. Kariadi Semarang merupakan suatu pemeriksaan kedokteran nuklir terpilih untuk deteksi dini proses metastase kanker ke tulang dan paling banyak dilakukan. Pemeriksaan ini menggunakan radiofarmaka yang disuntikkan melalui pembuluh darah vena di tangan. Informasi yang diperlukan sebelum dilakukan pemeriksaan bone scan antara lain riwayat kanker pasien, penyakit tulang, fraktur dan trauma, keluhan pasien seperti nyeri dan keterbatasan gerak, riwayat kemoterapi dan radioterapi, riwayat pemeriksaan radiologi sebelumnya, terpasang pacemaker dan prothesa.

Persiapan pasien pasien sebelum dilakukan pemeriksaan bone scan antara lain : 
1. Informasikan ke petugas medis :

a. Apabila pasien sedang dalam keadaan hamil atau menyusui, dan apabila pasien memiliki riwayat alergi atau sensitivitas terhadap obat-obatan, zat kontras atau iodium.

b. Beberapa hari sebelumnya telah melakukan pemeriksaan yang mengandung barium (misalnya barium enema) atau sedang mengkonsumsi obat yang mengandung bismuth (misalnya pepto-bismuth) karena kedua zat tersebut dapat berpengaruh terhadap hasil pemeriksaan.

2. Kurangi konsumsi cairan 4 jam sebelum pemeriksaan dilakukan karena pasien akan diminta umtuk mengkonsumsi banyak cairan setelah penyuntikan radiofarmaka .

3. Setelah radofarmaka Tc99m-MDP (methylenediphosphonate) disuntikkan, pasien harus menunggu 3-5 jam sebelum pemeriksaan bone scan dilakukan. Oleh karena itu pasien diperbolehkan membawa buku, majalah atau barang lainnya untuk memanfaatkan waktu pada saat menunggu pengambilan gambar.

4. Sebelum pemeriksaan dilakukan, lepaskan perhiasan atau benda logam lainnya yang dikenakan pasien karena dapat menggangu pencitraan.

Radiofarmaka yang digunakan adalah Tc99mMDP (methylenediphosphanate) memiliki waktu paruh fisik 6,01 jam, energi $140 \mathrm{KeV}$ dengan dosis untuk dewasa 20-30 mCi (740-1110 MBq); untuk anak $0,25 \mathrm{mCi} / \mathrm{kg}(2,22 \mathrm{MBq} / \mathrm{kg})$ dengan dosis minimum $1 \mathrm{mCi}$ (37 $\mathrm{MBq})$. Persiapan radiofarmaka dilakukan di ruang Hot Lab.

Peralatan yang diperlukan dalam pemeriksaan bone scan antara lain :

1. Kamera gamma yang sudah di daily QC + Spect CT dilengkapi data prosesor :

a. Collimator : LEHR (Low Energy High Resolution)

b. Exposure time per pixel : $700 \mathrm{sec} / 8 \mathrm{~cm}$.

c. Zoom Factor : 1.0

d. Bentuk aqusisi pada kamera gamma untuk teknik pencitraan secara dinamik dan statik

e. Puncak energi : $140 \mathrm{KeV}$

f. Window wide : $20 \%$

g. Auto contour On

h. Scan lenght $200 \mathrm{~cm}$

i. Scan speed $15 \mathrm{~cm} / \mathrm{min}$

2. Spuit dan jarum suntik disposible

3. Perisai tabung suntik

4. Alkohol swab

5. Handscoon

\section{Hasil dan Pembahasan}

Tatalaksana pemeriksaan bone scan di Instalasi Radiologi RSUP Dr. Kariadi Semarang dilakukan sebagai berikut :

1. Sebelum pemeriksaan dilakukan, dokter akan menjelaskan prosedur pemeriksaan bone scan terlebih dahulu.

2. Pasien atau keluarga pasien diminta untuk menandatangani surat persetujuan tindakan untuk pemeriksaan bone scan.

3. Pasien akan disuntikan radiofarmaka Tc-99mMDP (methylenediphospho-nate dengan dosis $15-20 \mathrm{mCi}$, melalui pembuluh darah vena di tangan.

4. Pengambilan pencitraan bisa dilakukan segera setelah radiofarmaka disuntikkan atau beberapa saat sesudahnya untuk menunggu radiofarmaka terdistribusi dan diserap oleh tulang kurang lebih 3-5 jam kemudian.

5. Pada saat akan dilakukan pemeriksaan, pasien dianjurkan untuk buang air kecil dahulu, karena kandung kemih yang penuh akan mengganggu gambaran tulang panggul.

6. Pasien diposisikan terlentang di atas meja pemeriksaan dan diinstruksikan untuk tidak bergerak selama pemeriksaan, karena setiap gerakan dapat mengganggu kualitas hasil pemeriksaan.

Pemeriksaan kedokteran nuklir bone scan di Instalasi Radiologi RSUP Dr.Kariadi Semarang pada umumnya hanya dilakukan satu fase saja yaitu fase ketiga (fase total body) yaitu pemeriksaan dilakukan 3-5 jam setelah pemberian radiofarmaka, tetapi pada kasus tertentu seperti osteosarkoma, biasanya dilakukan 3 fase pemeriksaan yaitu fase pertama (fase vaskuler), fase kedua (fase blood pool) dan fase ketiga (fase total body).

Hal-hal yang perlu diperhatikan setelah selesai pemeriksaan bone scan dilakukan antara lain :

1. Setelah pemeriksaan selesai pasien dianjurkan untuk bangun secara perlahan-lahan dari meja pemeriksaan agar tidak merasa pusing atau melayang akibat berbaring lama.

2. Pasien dianjurkan banyak minum air dan sering buang air kecil selama 24 - 48 jam setelah pemeriksaan untuk membantu mengeluarkan zat radioaktif atau radiofarmaka yang tersisa di tubuh.

3. Jika setelah sampai di rumah, apabila pasien merasakan adanya rasa nyeri, timbul kemerahan 
di kulit dan atau bengkak pada daerah tempat radiofarmaka disuntikkan, maka segera memberitahukan dokter.

4. Tidak melakukan pemeriksaan radionuklida lainnya dalam waktu $24-48$ jam setelah pemeriksaan selesai.

5. Selama tubuh pasien memancarkan sinar radioaktif maka pasien dilarang untuk berdekatan dengan anak kecil dan wanita hamil.

6. Pasien dapat melakukan aktivitas dan makan seperti biasa, kecuali dokter mengatakan sebaliknya, tergantung dari kondisi masingmasing pasien.

\section{Pemeriksaan Satu Fase}

Dilakukan apabila letak dari kanker primer telah diketahui dan untuk melihat ada atau tidaknya metastasis pada tulang dengan prosedur pemeriksaannya sebagai berikut :

1. Input data pasien pada bagian administrasi.

2. Persiapkan alat dan bahan yang akan digunakan.

3. Pasien dipanggil ke ruang suntik, kemudian suntikkan radiofarmaka Tc-99m MDP secara intra vena.

4. Setelah penyuntikan,pasien menunggu 3-5 jam agar radiofarmaka sudah merata ke seluruh tulang.

5. Pasien dipersilahkan untuk masuk ke ruang pemeriksaan,sebelum dilakukan pemeriksaan pasien diinstruksikan untuk buang air kecil terlebih dahulu.

6. Posisikan pasien supine diatas meja pemeriksaan dan diinstruksikan untuk tidak bergerak selama pemeriksaan.

7. Lakukan proses scanning selama 15-20 menit. Jika dokter menganjurkan untuk dilakukan Spect CT maka lakukan pemeriksaan tersebut.

8. Setelah selesai dilakukan scanning, pasien diinstruksikan untuk menunggu di ruang perawatan.

9. Lakukan processing data.

10. Pasien diperbolehkan untuk pulang apabila waktu paruh sudah meluruh.

\section{Pemeriksaaan Tiga Fase}

Dilakukan apabila letak dari kanker primer belum diketahui, sekaligus melihat ada atau tidaknya metastasis pada tulang dengan prosedur pemeriksaan sebagai berikut :

1. Input data pasien pada bagian administrasi.

2. Persiapkan alat dan bahan yang akan digunakan.

3. Pasien dipersilahkan untuk masuk ke ruang pemeriksaan, sebelum dilakukan pemeriksaan pasien diinstruksikan untuk buang air kecil terlebih dahulu.
4. Posisikan pasien supine diatas meja pemeriksaan dengan bagian tubuh yang diperiksa berada dipertengahan detektor.

5. Suntikkan radiofarmaka Tc-99m MDP secara intravena.

6. Bersamaan penyuntikkan langsung dilakukan scanning pertama yang bertujuan untuk melihat vaskulerisasi di daerah target (Fase vaskuler).

7. Setelah itu dilakukan scanning fase kedua (fase blood pool) yang bertujuan untuk melihat akumulasi dari radiofarmaka yang disuntikkan.

8. Setelah fase kedua selesai, pasien menunggu untuk dilakukan scanning kembali fase ketiga.

9. Pasien dipersilahkan kembali masuk ruang pemeriksaan setelah 3-5 jam paska pemberian radiofarmaka, posisikan supine diatas meja pemeriksaan.

11. Lakukan proses scanning selama 15-20 menit. Jika dokter menganjurkan untuk dilakukan Spect CT maka lakukan pemeriksaan tersebut.Fase ketiga ini bertujuan untuk melihat keseluruhan tulang (fase total body).

10. Setelah selesai dilakukan scanning, pasien dipersilahkan menunggu di ruang perawatan hingga waktu paruh meluruh.

11. Lakukan processing data.

12. Pasien diperbolehkan untuk pulang apabila waktu paruh sudah meluruh.

Berikut posisi pasien pada saat pemeriksaan bone scan di Instalasi Radiologi RSUP Dr.Kariadi Semarang :

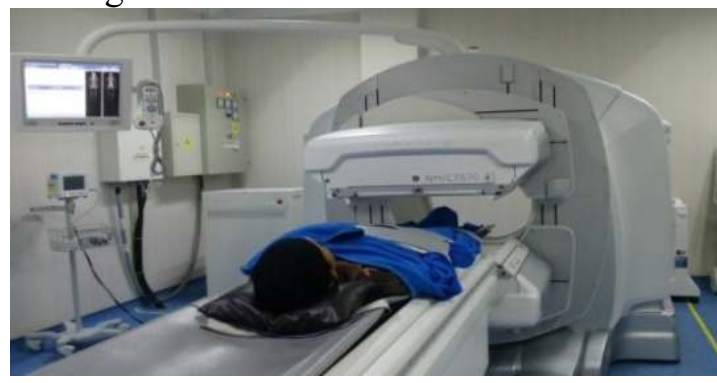

Gambar 1. Posisi Pasien Anterior posterior

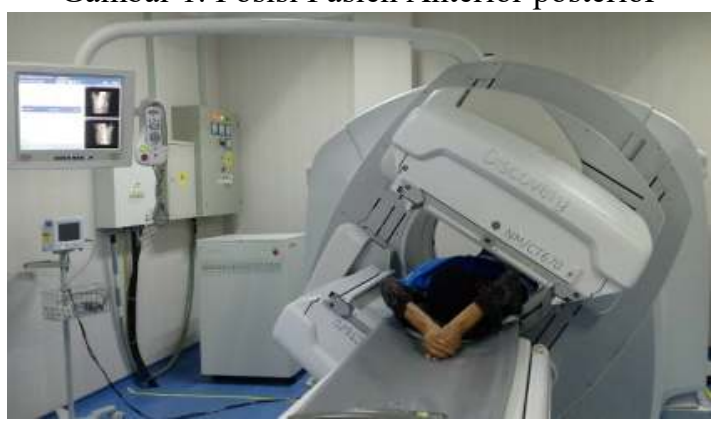

Gambar 2. Posisi Pasien Oblik

Proses jalannya pemeriksaan 
Proses jalannya pemeriksaan bone scan dimulai dengan menyuntikkan zat radioaktikf atau radiofarmaka ke pembuluh darah vena ditangan. Radiofarmaka tersebut selama beberapa jam selanjutnya akan diambil oleh sel-sel di tubuh yang bertugas memproduksi tulang. Sel-sel pembuat tulang ini kebanyakan akan berada pada daerah tulang yang terkena penyakit, dimana produksi tulang baru diperlukan untuk menambal daerah yang berlubang atau rusak.Kamera khusus digunakan untuk memindai (scanning) seluruh badan. Pengambilan pencitraan bisa dilakukan segera setelah radiofarmaka disuntikkan atau beberapa saat sesudahnya untuk menunggu radiofarmaka terdistribusi dan diserap oleh tulang, kurang lebih 3-5 jam kemudian.

Pada layar pemindai akan terlihat gambaran daerah dengan aktivitas tulang yang berlebihan (areas of extra bone activity), yang biasanya ada di daerah serangan kanker dan peradangan sendi (arthritis). Hal ini terjadi karena radiofarmaka berkumpul di daerah di mana terdapat aktivitas pembentukan tulang baru.Daerah dengan aktivitas pembentukan tulang baru ini akan terlihat sebagai gambaran yang gelap pada gambar.Perlu diketahui, bahwa bagian tulang apapun bisa terkena kanker.

Hasil pencitraan pemeriksaan kedokteran nuklir bone scan di Instalasi Radiologi RSUP Dr. Kariadi Semarang sebagai berikut:

1. Pada keadaan normal distribusi radioaktivitas pada tulang tampak simetris. Penangkapan radioaktivitas relatif tinggi pada persendian (growth plate) terutama pada anak-anak, kedua ginjal akan tampak menangkap radioaktivitas yang disebabkan ekskresi radiofarmaka yang tidak digunakan melalui ginjal.Pengamatan harus lebih hati-hati apabila kandung kemih tidak benar-benar kosong.

2. Pada proses metastase ke tulang akan tampak penangkapan radioaktivitas patologis yang khas bisa multipel (multiple hot spots). Apabila proses metastase sangat luas sering diperoleh gambaran yang disebut superscan, yaitu hots spots yang multipel tanpa radioaktivitas pada kedua ginjal. Proses metastase dengan ditemukan gambaran single hots spots sangat jarang, namun apabila ditemukan penangkapan radioaktivitas yang meningkat secara difus pada tulang iga penderita karsinoma mammae harus dicurigai sebaga proses metastase tunggal.

3. Tumor ganas dapat dibedakan dari tumor jinak dengan pemeriksaan blood pool. Pada tumor ganas akan diperoleh gambaran peningkatan vaskularisasi (hiperemik), sedangkan pada tumor jinak biasanya menunjukan vaskularisasi yang kurang (hipoperfusi). Kecuali pada osteoid osteoma walaupun merupakan tumor jinak, namun memberikan gambaran hiperemik.

4. Bone scan merupakan pemeriksaan yang dapat diandalkan untuk diagnosis dini osteomielitis dan arthritis septik. Pemeriksaan ini dapat memberikan nilai positif beberapa hari sampai beberapa minggu sebelum tampak dengan pemeriksaan radiologi.

5. Pada stadium awalan ekrosisa septik akan ditemukan gambaran radioaktivitas yang berkurang pada kaput femoris, sedangkan pada stadium lanjutkan diperoleh gambaran sebaliknya, yaitu peningkatan radioaktivitas yang disebabkan adanya revaskularisasi.

6. Pada penyakit metabolic tulang seperti penyakit paget, penangkapan radioaktivitas meningkat secara difus pada khususnya tulang-tulang panjang.

7. Banyak dari gambaran abnormal yang tampak pada bone scan bukan kanker.Pada peradangan sendi, zat radioaktif atau radiofarmaka cenderung terlihat di permukaan sendi, tidak di dalam tulang.Akan tetapi sangat sulit membedakan antara peradangan (arthritis) dan kanker, khususnya pada tulang punggung.Hal ini disebabkan karena tulang punggung terdiri dari banyak tulang berukuran kecil dan banyak bagian sendi yang berukuran kecil.Jika terlihat ada perubahan pada tulang punggung, sebaiknya pemeriksaan atau evaluasi lebih jauh perlu dilakukan.

Hasil gambar pencitraan bone scan dengan 3 fase pada kasus osteosarkoma femur sinistra di Instalasi Radiologi RSUP Dr.Kariadi Semarang :

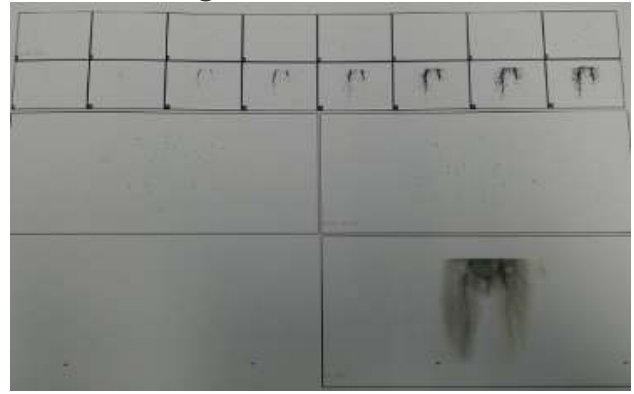

Gambar 3. Fase vaskuler dan fase blood pool 


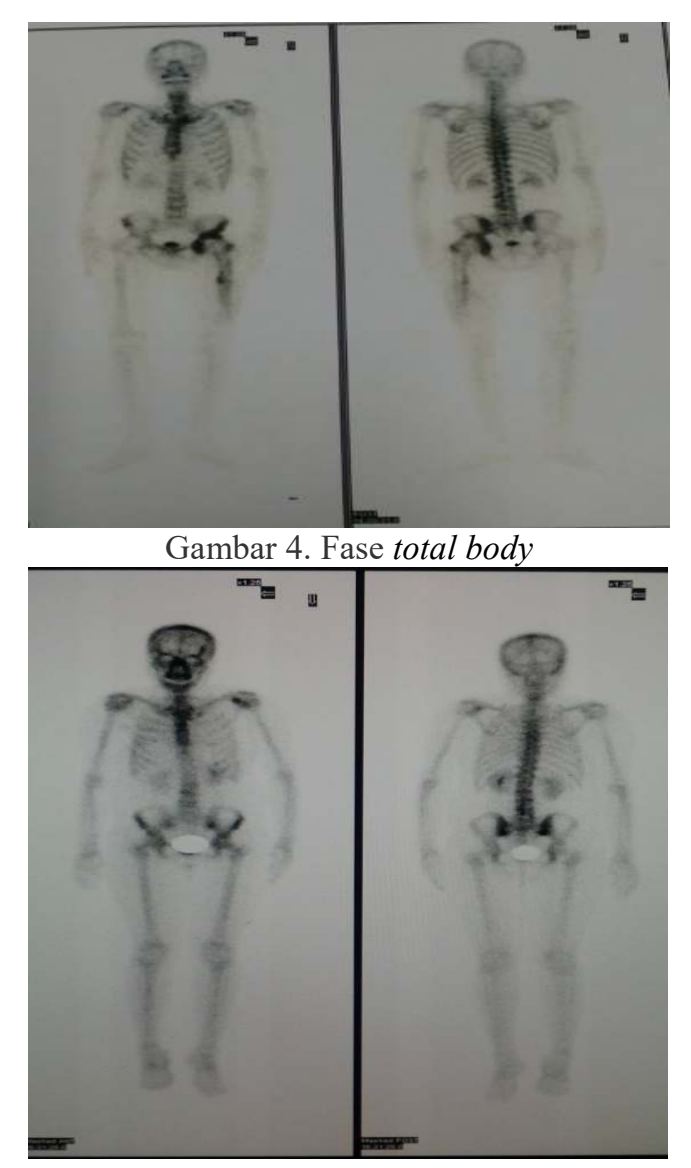

Gambar 5. Bone scan anterior posterior (normal)
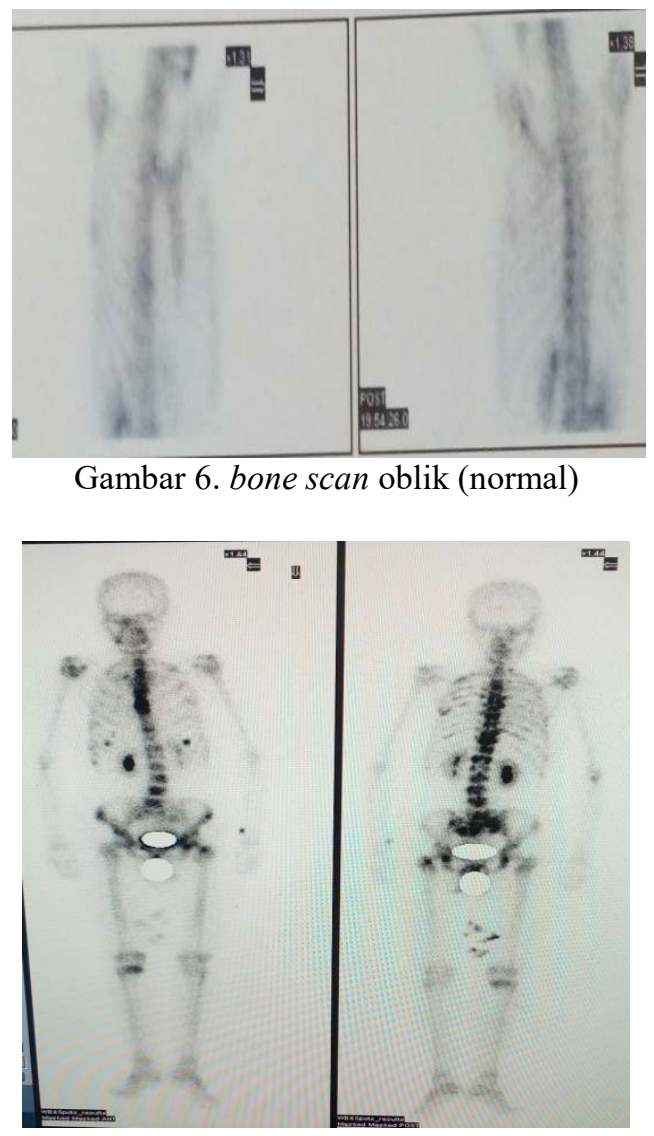

Gambar 7. Bone scan anterior posterior (metastase tulang)

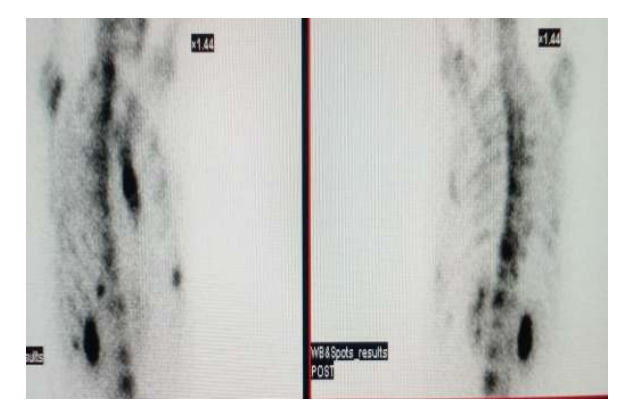

Gambar 8. Bone scan oblik (metastase tulang)

\section{Simpulan}

Pemeriksaan kedokteran nuklir bone scan di Instalasi Radiologi RSUP Dr. Kariadi Semarang merupakan pemeriksaan terpilih untuk deteksi dini proses metastase kanker ke tulang dengan menggunakan zat radioaktif atau radiofarmaka Tc99m-MDP (methylenediphosphonate) sebanyak $15-20 \mathrm{mCi}$ yang disuntikkan intra vena melalui pembuluh darah vena di tangan, pada umumnya hanya dilakukan satu fase saja yaitu fase ketiga (fase total body) yang dilakukan 3-5 jam pasca penyuntikan radiofarmaka.

Banyak dari gambaran abnormal yang tampak pada bone scan bukan kanker. Pada peradangan sendi, zat radioaktif atau radiofarmaka cenderung terlihat di permukaan sendi, tidak di dalam tulang. Akan tetapi sangat sulit membedakan antara peradangan (arthritis) dan kanker, khususnya pada tulang punggung.

Keunggulan pemeriksaan sidik tulang adalah dapat mendeteksi kelainan yang terjadi pada tulang 3-6 bulan lebih awal sebelum terjadi kerusakan tulang akibat proses keganasan. Pasien dengan riwayat keganasan perlu waspada terhadap penyebaran sel kanker ke tulang. Terlebih, jika muncul gejala nyeri yang tidak wajar dan tulang mudah patah, maka untuk segera memeriksakan diri melalui pemeriksaan bone scan.

\section{Daftar Pustaka}

Cheran, S. K., Herndon, J. E., \& Patz, E. F. (2004). Comparison of Whole-body FDG-PET to Bone Scan for Detection of Bone Metastases in Patients with a New Diagnosis of Lung Cancer. Lung Cancer, 44(3), 317-325. https://doi.org/10.1016/j.lungcan.2003.11.008 D, D. C. (2011). Bone Scan Medice Plus.

GE Medical Health. (2005a). Manual Book of Infinia.

GE Medical Health. (2005b). Xeleris Processing.

Jana, S., \& Blaufox, M. D. (2006). Nuclear Medicine Studies of the Prostate, Testes, and 
Bladder. Seminars in Nuclear Medicine,

36(1), 51-72.

https://doi.org/10.1053/j.semnuclmed.2005.0

9.001

Masjhur, J. S., \& Hussein, A. S. K. (1999). Buku

Panduan Tata Laksana Diagnostik dan

Terapi Kedokteran Nuklir. Terapi Kedokteran Nuklir.

Shie, P., Cardarelli, R., Brandon, D., Erdman, W., \& AbdulRahim, N. (2008). Meta-analysis: Comparison of F-18 FluorodeoxyglucosePositron Emission Tomography and Bone Scintigraphy in the Detection of Bone Metastases in Patients With Breast Cancer. Clinical Nuclear Medicine, 33(2), 97-101. https://doi.org/10.1097/RLU.0b013e31815f2 $3 \mathrm{~b} 7$

Van den Wyngaert, T., Strobel, K., Kampen, W. U., Kuwert, T., van der Bruggen, W., Mohan, H. K., Gnanasegaran, G., Delgado-Bolton, R., Weber, W. A., Beheshti, M., Langsteger, W., Giammarile, F., Mottaghy, F. M., \& Paycha, F. (2016). The EANM practice guidelines for bone scintigraphy. European Journal of Nuclear Medicine and Molecular Imaging, 43(9), 1723-1738. https://doi.org/10.1007/s00259-016-3415-4

Weiner, R. E. (2006). The Scientic Basic of Nuclear Medicine, Bone Imaging Radiopharmaceuticals, Technetium $99 \mathrm{~m}$ Diphosphonates, Biologic Behavior (2nd ed.). Mosby Elsevier.

Yudistiro, R. (2012). Kedokteran Nuklir : Apa dan Bagaimana? 